\title{
PELATIHAN PENGGUNAAN SOFTWARE MAPLE DALAM MENINGKATKAN PEMAHAMAN MATERI OSN TEORI BILANGAN DAN ALJABAR BAGI GURU MATEMATIKA TINGKAT SMA SE KABUPATEN PELALAWAN
}

\author{
Supriadi Putra'), Zulkarnain ${ }^{2)}$, dan Khozin Mu'tmara ${ }^{3)}$ \\ 1,2,3) Jurusan Matematika FMIPA Universitas Riau, Indonesia \\ E-mail : esputra@gmail.com
}

\begin{abstract}
ABSTRAK
Universitas Riau sebagai salah satu lembaga penyelenggara pendidikan tinggi di Provinsi Riau mempunyai kewajiban untuk meningkatkan mutu dan professionalisme guru sebagai tenaga pendidik di sekolah. Melalui kegiatan pengabdian kepada masyarakat sudah banyak kegiatan yang telah dilakukan. Salah satunya adalah kegiatan yang telah kami lakukan di Kabupaten Pelalawan. Kami dari Jurusan Matematika FMIPA Universitas Riau melakukan kegiatan pelatihan penggunaan software Maple guru untuk meningkatkan pemahaman guru dalam materi teori bilangan dan aljabar. Agar lebih menarik materi pelatihan dikaitkan dengan materi Olimpiade Sains sehingga lebih menantang bagi guru peserta kegiatan. Pelaksanaan kegiatanpun lebih banyak workshop dari pada teori. Menggunakan laptop atau notebook masing-masing terlihat guru sangat menikmati kegiatan pelatihan yang dilakukan. Dalam empat hari kegiatan yang dilakukan kehadiran peserta adalah $100 \%$. Sementara dari angket yang disebarkan $98 \%$ peserta merasa puas dengan adanya kegiatan ini . Kegiatan ini juga dapat dikatakan berhasil meningkatkan pemahaman guru dalam materi teori bilangan dan aljabar yaitu dengan melihat hasil pretes dan postes yang dilakukan. Lebih dari $97.5 \%$ peserta dapat menjawab dan menjelaskan dengan baik problem yang diberikan.
\end{abstract}

Kata kunci: Aljabar, Teori Bilangan, Software Maple, Olimpiade Sains

\begin{abstract}
University of Riau as one of the institutions providing higher education in Riau Province has an obligation to improve the quality and professionalism of teachers as educators in schools. Through community service activities, many activities have been carried out. One of them is the activity that we have done in Kabupaten Pelalawan. We from the Department of Mathematics, Faculty of Mathematics and Natural Sciences, University of Riau conduct training activities on the use of Maple teacher software to improve teacher understanding in numbers theory and algebra. In order to be more interesting the training material is linked to the Science Olympiad material so that it is more challenging for the teacher participating in the activity. There are more workshops than theoretical activities. Using a laptop or notebook each teacher looks really enjoyed the training activities carried out. Within four days the activity carried out attendance of participants was $100 \%$. While from the questionnaire distributed $98 \%$ of the participants were satisfied with this activity. This activity can also be said to be successful in increasing teacher understanding in number theory and algebra material by looking at the results of the pretest and posttest conducted. More than $97.5 \%$ of participants can answer and explain the problem given.
\end{abstract}

Key words: Algebra, Number theory, Maple Software, Science Olympiad 


\section{PENDAHULUAN}

Kabupaten Pelalawan dibentuk berdasarkan Undang-Undang No. 53 tahun 1999 dengan ibukota Pangkalan Kerinci dan diresmikan oleh Menteri Dalam Negeri Republik Indonesia pada tanggal 12 Oktober 1999, sekaligus diperingati sebagai "Hari Jadi Kabupaten Pelalawan".

Kabupaten Pelalawan merupakan salah satu Kabupaten dari 12 Kabupaten/Kota di Propinsi Riau, Kabupaten Pelalawan terletak di Pesisir Pantai Timur Provinsi Riau Pulau Sumatera. Secara geografis Kabupaten Pelalawan berada di 00 46,24' Lintang Utara sampai $00^{\circ} 24,34$ Lintang Selatan dan $101^{\circ} 30,37^{\prime}$ Bujur Timur sampai dengan $103^{\circ} 21,36^{\prime}$ Bujur Timur. Kabupaten Pelalawan berbatasan dengan : (1) Sebelah utara berbatasan dengan Kabupaten Siak, (2) Sebelah Selatan berbatasan dengan Kabupaten Indragiri Hulu dan Kabupaten Indragiri Hilir, (3) Sebelah barat berbatasan dengan Kabupaten Kampar dan Kota Pekanbaru dan (4) Sebelah Timur berbatasan dengan Kabupaten Karimun Provinsi Kepulauan Riau.

Luas Kabupaten Pelalawan 13.256,7 km² yang terdiri dari 12 kecamatan dengan kecamatan terluas adalah Kecamatan Teluk Meranti yaitu $4.246 \mathrm{~km}^{2}$ (32,03 persen) dan yang paling kecil adalah Kecamatan Pangkalan Kerinci dengan luas 192,5 $\mathrm{km}^{2}$ atau 1,45 persen dari luas Kabupaten Pelalawan.

Perkembangan Kabupaten Pelalawan yang demikian pesat telah menarik sangat banyak penduduk pendatang baik yang akhirnya menetap maupun tidak menetap, keadaan ini menjadikan Kabupaten Pelalawan berpenduduk multi etnis.

Salah satu ciri demografi Indonesia adalah sebaran penduduk yang tidak merata, hal yang sama juga terjadi di Kabupaten Pelalawan. Sebagian besar 95.722 jiwa (26\%) penduduk Kabupaten Pelalawan berdomisili di ibukota kabupaten, sisanya menyebar di kecamatan. Kecamatan yang paling sedikit jumlah penduduknya adalah kecamatan Bandar Petalangan yaitu 14.253 (4\%).

Pemerintah daerah Kabupaten Pelalawan telah melakukan berbagai usaha serius dalam rangka meningkatkan kualitas masyarakatnya, baik dari segi fisik (kesehatan), aspek intelektualitas (pendidikan), aspek kesejahteraan ekonomi (daya beli), maupun moralitas (iman dan taqwa). Seluruh upaya pemerintah tersebut sejalan dengan strategi pembangunan kabupaten pelalawan yaitu meningkatkan derajat kesehatan masyarakat dan mutu pendidikan, serta meningkatkan peran serta masyarakat dalam proses pembangunan sehingga salah satu misi pembangunan Kabupaten Pelalawan untuk meningkatkan kesejahteraan rakyat dapat terwujud terutama dalam bidang kesehatan dan pendidikan.

Banyak pelatihan yang telah dilakukan baik oleh Pemerintah daerah, pusat maupun univesitas. Guru-guru yang terlibat dalam pelatihanpun jumlahnya cukup signifikan. Pelatihan yang dilakukan termasuk pelatihan terhadap guru bidang studi matematika seperti pemahaman materi dan kompetisi matematika. Universitas Riau juga telah melakukan usaha seperti pelatihan Persiapan Siswa Dalam menghadapi OSN dengan Pembinaan Guru Pendamping OSN SMP di Kota Dumai Zulfarina (2012). Isuisu yang mengatakan bahwa matematika sebagai ilmu yang sulit dan tidak menarik kiranya masih aktual hingga saat ini. Berbicara tentang materi olimpiade sains maka sangat banyak guru yang menghidar darinya. Hal itu juga yang menyebabkan sulit mendapatkan bibit unggul daerah (siswa yang mampu) untuk bersaing dalam perlombaan olimpiade sains. Sehingga sampai saat ini terkesan kesempatan bersaing dalam bidang olimpiade sains hanya untuk siswa yang ada dikota saja. Padahal itu adalah pandangan yang keliru karena semuanya punya kesempatan yang sama untuk 
bersaing. Dari pembicaraan kami dengan beberapa orang guru khsusunya di Kabupaten Pelalawan, kami menangkap keluhan para guru yang belum pernah mendapatkan kesempatan pelatihan sehingga merasa tidak memiliki kemampuan dalam melatih siswanya sendiri.

Dari identifikasi masalah yang telah dijelaskan di atas, maka dapat dirumuskan permasalahan utama yaitu rendahnya motivasi guru dan siswa untuk mengikuti dan berprestasi dalam kegiatan perlombaan olimpiade sain. Untuk itu perlu dicari cara melatih guru bidang studi matematika sehingga mampu melatih muridnya dalam bersaing dibidang perlombaan seperti kegiatan Olimpiade Sains.

Sehingga akhirnya kami memberanikan diri mengajukan proposal untuk melakukan pelatihan kepada guru di Pelalawan. Kegiatan pelatihan ini ditujukan kepada guru-guru inti bidang studi Matematika tingkat SMA/MA se-Kabupaten Pelalawan Propinsi Riau. Berdasarkan pengalaman beberapa tahun sebelumnya, guuru-guru ini sudah tergabung dalam wadah MGMP (Musyawarah Guru Mata Pelajaran) dan sudah aktif melakukan kegiatan bersama minimal sekali sebulan.

Adapun tujuan dari kegiatan pelatihan ini adalah (1) memberikan konsep pemahaman dan penguasaan materi olimpiade sains, (2) memberikan motivasi untuk meningkatkan kompetensi siswa, (3) membimbing guru-guru untuk dapat berinovasi dalam menyampaikan materi dan pembahasan soal, (4) membimbing guru-guru untuk bisa menggunakan software maple sehingga dapat digunakan untuk menjawab dan memodifikasi soal olimpiade sains. Sedangkan manfaat dari kegiatan ini nantinya adalah (1) bagi sekolah dapat meningkatkan mutu sekolah, (2) bagi guru dapat mendapatkan ilmu dan lebih percaya diri membina siswanya dalam materi olimpiade sains dan materi sekolah lainnya, (3) tersedianya bahan ajar materi olimpiade sain kelompok MGMP Matematika SMA/MA Kabupaten Pelalawan.

\section{TINJAUAN PUSTAKA}

\section{Olimpiade Sains}

Dari masa ke masa, OSN mengalami berbagai pembenahan. Mulai dari tingkat sekolah, kabupaten/kota, hingga provinsi, berlomba menyeleksi siswa terbaik yang nantinya akan berlaga di tingkat nasional. Di ajang OSN inilah kelak bermunculan para jenius muda yang akan mengharumkan nama bangsa di tingkat internasional.

Sejarah pelaksanaan OSN dimulai tahun 2002, saat Indonesia dipercaya menjadi tuan rumah Olimpiade Internasional Fisika. "Kala itu, sesuai dengan arahan Dirjen Pendidikan Dasar dan Menengah, Indra Djati Sidi, bahwa kita harus siap melaksanakan kegiatan ini dan harus siap pula mencapai tiga sukses, yaitu sukses penyelenggaraan, sukses peserta dan sukses prestasi. Three success itu berhasil dilaksanakan oleh tim Indonesia dengan perolehan 3 medali emas, dan 2 medali perak. Ajang ini diikuti oleh 72 negara di Bali. Kita mendapat kesan yang cukup baik di mata internasional. Dan olimpiade ini dibuka oleh Presiden RI, Megawati." Tutur Suharlan, SH, MM. "Usai pelaksanaan olimpiade, tim pelaksana punya mimpi, mengapa kegiatan ini tidak dilaksanakan di Indonesia dan bersifat nasional," lanjut Kasi Bakat dan Prestasi Direktorat Pembinaan SMA. Kegiatan itu menurut Suharlan kembali, memperoleh respon positif dari Mendiknas saat itu, Malik Fajar. Ia berpesan pada rektor yang hadir di acara tersebut untuk berfikir cerdas, kalau perlu siswa tingkat nasional diterima di UMPTN dan mengambil anak-anak yang berprestasi dari ajang ini. Selanjutnya, mantan mendiknas meminta agar mulai tahun depan, SD, SMP, dan SMA melaksanakan 
olimpiade."Kami kemudian berkoordinasi dengan Direktorat terkait, seperti SD, SMP dan SMA untuk menyusun langkah- langkah persiapan, mekanisme dan pelaksanaan, termasuk pembuatan logo, medali emas, perak dan perunggu, juga the best theory dan the best experiment. Saat itu pelaksanaannya belum begitu sempurna. Ajang bergengsi yang diikuti siswa SMA seluruh Indonesia ini, kemudian disempurnakan pada tahun 2003. Tahun itu pelaksanaan OSN sudah berkordinasi dengan SD, SMP dan SMA, kemudian disusul dengan pembuatan Standar Operasional Prosedur (SOP)."

Seiring berjalannya waktu, timbul keinginan agar penyelenggaraan OSN tingkat nasional bergiliran di adakan di semua provinsi. Aturan-aturan yang ada di dalam SOP kemudian diberlakukan. Selanjutnya, OSN pun dilaksanakan secara rutin setiap tahunnya. Dari sinilah akhirnya perjalanan OSN terus berlanjut. Pada tahun 2004 berlangsung di Pekanbaru (Riau), kegiatan ini sudah melibatkan SD, SMP, dan SMA, dan respon positif datang dari berbagai provinsi. Setelah beberapa tahun berikut digilir tempat pelaksaannya, maka pada tahun 2018 yang lalu lomba OSN kembali dilakukan di Riau. Akan tetapi dari fakta lapangan yang ditemui untuk peserta dari Riau, sebagian peserta adalah siswa sekolah dikota pekanbaru. Hanya sedikit peserta yang berasal dari luar kota pekanbaru.

Dalam ajang OSN di tingkat nasional peserta mengikuti serangkaian kegiatan tes, baik teori maupun eksperimen. Dalam mengikuti tes olimpiade ini kadang siswa medapatkan kesulitan dalam mengerjakan soal seperti yang dikatakan Rajali Rasyid, (2006) dalam makalahnya, beliau mengatakan bahwa masih banyak siswa yang kesulitan soal olimpiade hal ini dikarenakan ada kesenjangan antara pengalaman yang mereka miliki dengan tingkat kesulitan soal.

Selain kesulitan di atas waktu juga kadang menjadi kendala para peserta tes sebagai contoh dalam pelaksanan OSN 2018 di Pekanbaru dalam soal teori ada jumlah soal 63 peserta hanya di berikan kesempatan mengerjakan soal dalam waktu 60 menit dengan berbagai jenis soal sehingga dari hal ini dibutuhkan keahlian atau teknik untuk mengerjakan soal. Dari beberapa hal di atas maka diperlukan upaya pembinaan sejak dini untuk mempersiapkan anak didik dalam menghadapi ajang olimpiade baik itu dari sekolah maupun dari daerah. Sesuai dengan ungkapan Rajali Rasyid (2006) bahwa faktor kesiapan dan iklim kompetisi dalam ajang olimpiade dapat diatas dengan penjaringan dan pembinaan sedini mungkin dan melakukan pembinaan baik itu pada siswa maupun guru.

\section{Maple}

Maple adalah program komputer yang dikembangkan pertama kali pada tahun 1980 oleh Grup Symbolic Computation di University of Waterloo Ontario, Kanada untuk keperluan bidang matematika, statistika dan komputasi aljabar. Maple adalah suatu program interaktif yang mengintegrasikan kemampuan komputasi baik numerik ataupun simbolik, visualisasi (grafik) dan pemrograman”. Program Maple ini dapat dikatakan sangat canggih dan sangat membantu sekali dalam menyelesaikan berbagai topik matematika, seperti analisis numerik, aljabar simbolik, kalkulus, persamaan diferensial, aljabar linear, simulasi dan visualisasi. Maple mempunyai banyak versi dan latest versionnya adalah Maple versi 2019, Widdya Rahmalina (2018). Akan tetapi dalam kegiatan ini kami akan menggunakan software Maple versi 13.

Dengan Maple, kita dapat membuat dokumen interaktif yang memungkinkan kita mulai memecahkan masalah matematika dengan memasukkan ekspresi Matematika dalam 2-D yang menggunakan point-and-klik antarmuka. Kita dapat menggabungkan 
"text" dan ekspresi matematika di baris yang sama, menambahkan tabel untuk mengatur isi dari pekerjaan Anda, atau menyisipkan gambar, sketsa daerah, dan spreadsheet. Kita juga dapat memvisualisasikan dan menghidupkan masalah dalam dua dan tiga dimensi, format teks untuk makalah akademis atau buku, dan masukkan hyperlink ke file Maple, atau alamat email. Dengan berbagai kelebihan Maple maka Maple telah digunakan oleh jutaan pemakai di seluruh dunia di kalangan pendidikan, lembaga riset, dan industri.

Dalam kegiatan pengabdian ini kami akan menggunakan software Maple untuk menyelesaikan persoalan yang berkaitan dengan bentuk aljabar dan teori bilangan. Persoalan tersebut banyak ditemukan dalam ajang kompetisi matematika seperti perlombaan OSN Matematika, baik untuk tingkat Kabupaten, Propinsi maupun Nasional.

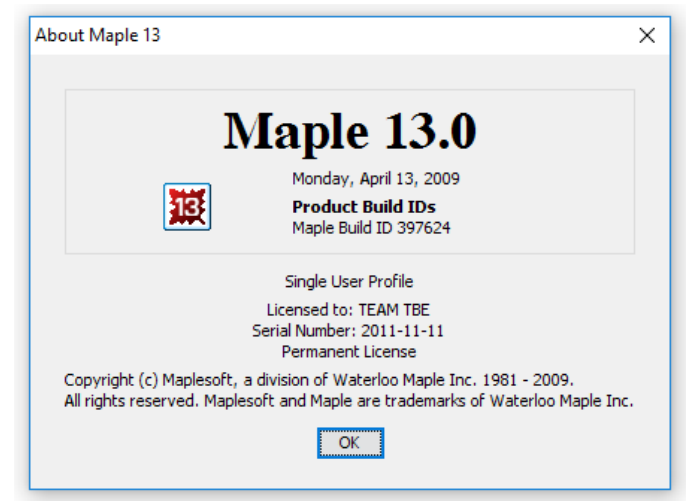

Gambar 1. Maple versi 13

\section{METODE PELAKSANAAN}

Kegiatan pengabdian ini dilakukan melalui pola kerja sama yang saling menguntungkan antara Tim Pengabdi dari Universitas Riau dan MGMP (Musyawarah Guru Mata Pelajaran) Matematika SMA Kabupaten Pelalawan. Kegiatan akan dilakukan di salah satu tempat di Pangkalan Kerinci. Sementara jumlah peserta dibatasi hanya 20 orang guru yang dipilih oleh pihak MGMP dan berasal dari delapan sekolah yang berbeda. Untuk mencapai tujuan yang diharapkan dari kegiatan ini maka perlu dilakukan perencanaan sebaik-baiknya. Tahapan awal adalah pemilihan peserta kegiatan yang mempunyai kemampuan dan waktu untuk konsisten mengikuti pelatihan. Pemilihan peserta yang diharapkan diserahkan kepada MGMP Matematika SMA/MA Kab Pelalawan. Selanjutnya akan disepakati jadwal kegiatan. Karena kedua belah pihak mempunyai pekerjaan utama sebagai dosen dan guru, maka perlu ditetapkan jadwal untuk empat kali pertemuan sehingga tidak mengganggu kegiatan utama masingmasing. Sementara jadwal rutin bulanan MGMP adalah setiap hari Rabu, maka kedua belah pihak sepakat akan melakuan kegiatan pelatihan sekali dalam sebulan tepat pada hari rabu.

Sementara itu, penyampaian materi nantinya berbentuk: ceramah, diskusi/tanya jawab, dan kerja lab. Setiap peserta diwajibkan membawa laptop/notebook sendiri. Demi kelancaran kegiatan, bantuan teknis juga akan diberikan oleh mahasiswa KKN/KUKERTA di daerah pelaksanaan kegiatan. Untuk meningkatkan pemahaman materi, peserta akan diberikan tugas mandiri setelah masing-masing topik diberikan. 
Diantara beberapa kegiatan yang akan dilakukan, maka kegiatan pelatihan yang menjadi bagian yang sangat penting. Tahapan pelaksanaan kegiatan pelatihan yang disusun Tim Pengabdi adalah sebagai berikut:

a. Pada tahap awal kegiatan dilakukan pre test tentang Olimpiade Sain

b. Pada tahap pelatihan dilakukan pemberian materi oleh instruktur, diskusi materi antara guru dan instruktur dan kerja lab menggunakan software maple.

c. Pemberi tugas mandiri diantara setiap topik materi

d. Pada tahap akhir kegiatan dilakukan post test tentang Olimpiade Sain.

e. Tim pengabdi akan mengumpulkan bahan hasil diskusi dan diberikan narasi untuk dibuat menjadi modul sebagai hasil kegiatan.

Program pengabdian ini akan dikatakan berhasil apabila seluruh kegiatan yang direncanakan dapat dilaksanakan dengan baik dan mendapatkan output seperti yang diharapakan. Dalam hal ini output yang diharapkan adalah Modul Maple untuk Materi OSN : Aljabar dan Teori Bilangan.

\section{HASIL DAN PEMBAHASAN}

Tim Pengabdi Universitas Riau dalam kegiatan ini berjumlah tiga orang yaitu: Supriadi Putra, M.Si, Zulkarnain, M.Si dan Khozin Mu'tamar, M.Si. Kegiatan dilakukan di salah satu ruang serbaguna SMA Negeri 1 Pangkalan Kerinci. Sementara jumlah peserta dibatasi hanya 20 orang guru yang dipilih oleh pihak MGMP dan berasal dari delapan sekolah yang berbeda. Artinya ada satu sekolah mengutus lebih dari dua orang gurunya mengikuti kegiatan ini. Kegiatan dilakukan pada setiap hari Rabu sesuai dengan alokasi waktu MGMP Matematika. Jadwal kegiatan untuk empat kali tatap muka adalah sebagai berikut.

Tabel 1 : Jadwal Kegiatan

\begin{tabular}{llll}
\hline No & Hari / Tanggal & Waktu & Kegiatan \\
\hline 1. & Rabu, 7 Agustus 2019 & $09.00-09.30$ & Pembukaan Acara \\
\hline & & $09.30-10.30$ & Sesi 1 : Instalasi Software Maple \\
\hline & & $10.30-11.45$ & Sesi 2 : Pengantar Maple \\
\hline 2. & Rabu, 21 Agustus 2019 & $09.00-10.30$ & Sesi 1 : Aljabar OSN \\
\hline & & $10.30-11.45$ & Sesi 2 : Aljabar dengan Maple \\
\hline & & $13.30-15.30$ & Sesi 3 : Problem Solving \\
\hline 3. & Rabu, 11 Sept 2019 & $09.00-10.30$ & Sesi 1 : Teori Bilangan OSN \\
\hline & & $10.30-11.45$ & Sesi 2 : Teori Bilangan dengan Maple \\
\hline & & $13.30-15.30$ & Sesi 3 : Problem Solving \\
\hline & & & \\
& & $09.00-09.30$ & Sesi 1 : Penggunaan Modul hasil kerja \\
\hline & & $10.30-10.30$ & Sesi 2 : Modul - Aljabar \\
\hline & & $13.30-14.30$ & Sesi 3 : Modul - Teori Bilangan \\
\hline
\end{tabular}


Pada setiap kegiatan tatap muka, Tim Pengabdi menyampaikan materi sekaligus menggunakan software Maple sebagai alat bantu. Hasil diskusi dikumpulkan dan dinarasikan untuk dijadikan modul yang akan digunakan pada akhir kegiatan dan sekaligus merupakan output/luaran dari kegiatan pengabdian ini. Demikian juga diantara setiap tatap mukan akan diberikan tugas kepada peserta sehingga materi yang diberikan dalam pelatihan dapat dipahami lebih baik.

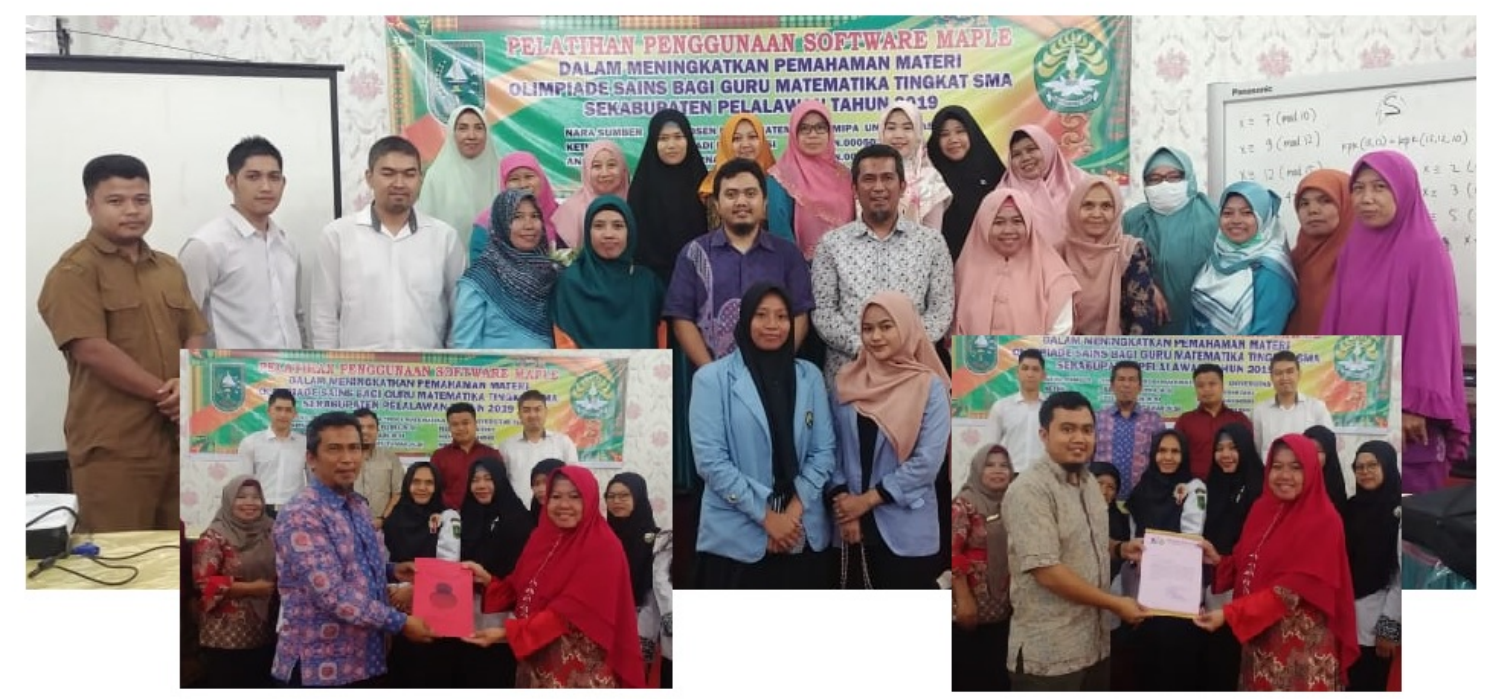

Gambar 2. Foto bersama, penyerahan modul dan sertifikat kegiatan

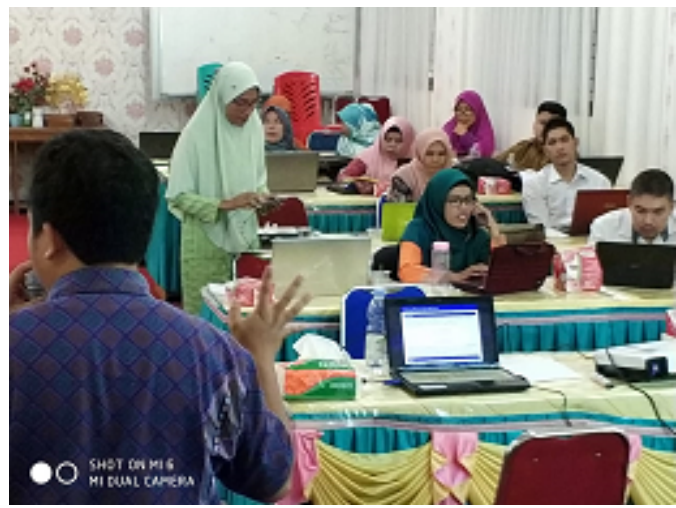

Gambar 3. Suasana kegiatan pelatihan

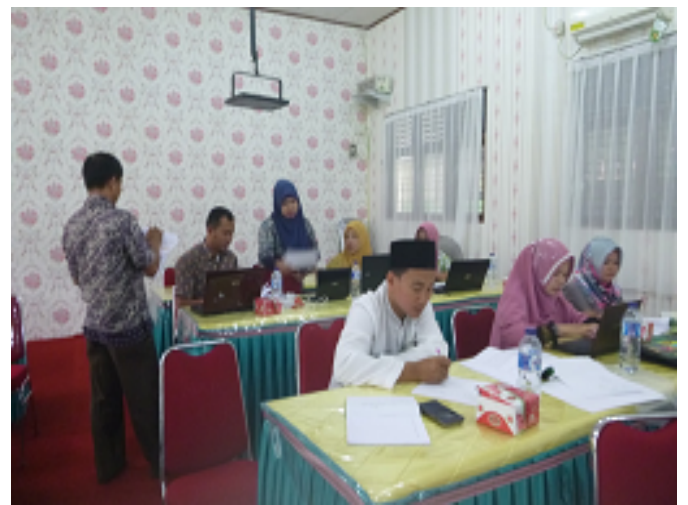

Gambar 4. Diskusi peserta pelatihan

Peserta yang mengikuti kegiatan pengabdian ini terlihat sangat antusias terutama dalam menggunakan software Maple dalam menyelesaikan problem solving yang berkaitan dengan materi Aljabar dan Teori Bilangan. Hal ini juga sesuai dengan data angket yang disebarkan Tim Pengabdia di akhir acara 98\% peserta mengatakan sangat setuju kalau acara ini kembali diadakan.

Sementara itu untuk mengukur penyerapan materi yang disampikan, Tim Pengabdi juga melakukan pre-test dan pos-test kepada peserta diawal dan diakhir kegiatan. Dari analisis hasil pre-test dan post-test tersebut terlihat dengan sangat signifikan $97.5 \%$ terjadi peningkatan pemahan guru dalam menyelesaikan problem solving yang berkaitan dengan soal OSN Matematika, terutama materi Aljabar dan Teori Bilangan. 
Setelah mengikuti kegiatan ini kami berharap peserta mendapatkan beberapa manfaat antara lain :

- Meningkatkan keterampilan dan kompetensi guru dalam pembahasan soal OSN Matematika

- Meningkatkan kepercayaan diri guru dalam pembinaan siswa disekolah untuk materi OSN Matematika

- Dapat menggunakan dan mengoperasikan software Maple dalam membantu pemahaman, pembahasan dan modifikasi soal OSN Matematika.

Pada hari terakhir pelatihan modul sebagai luaran utama kegiatan ini diserahkan kepada seluruh peserta kegiatan.

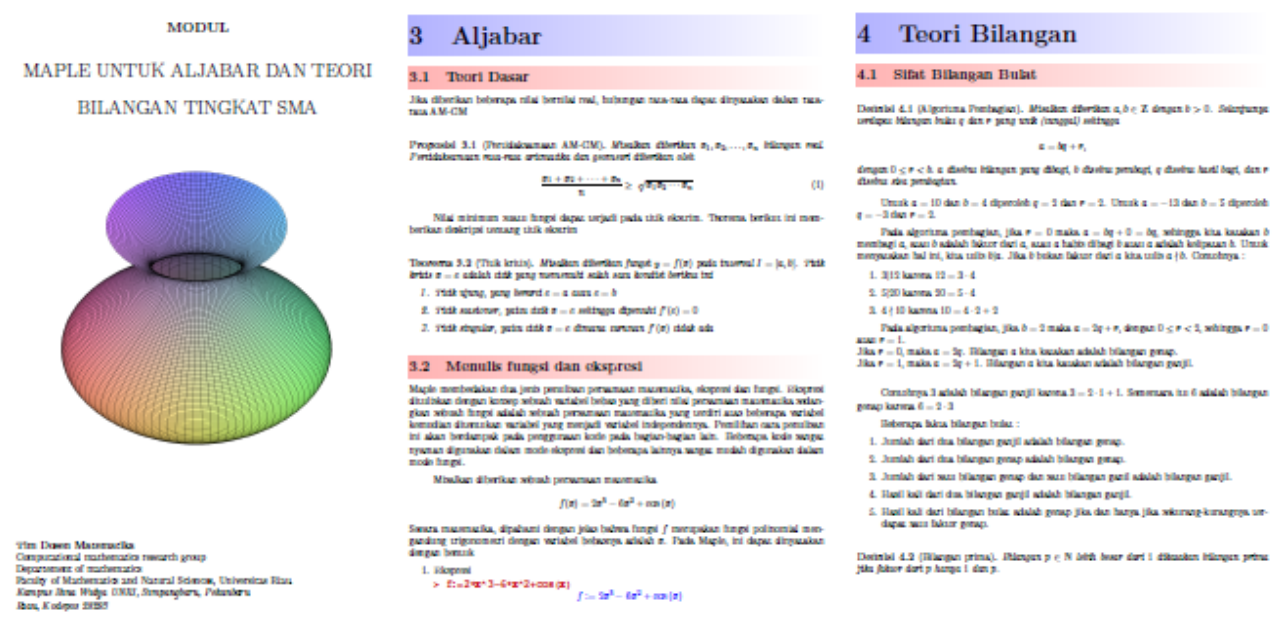

Gambar 4. Modul Hasil Kegiatan

\section{KESIMPULAN}

Kegiatan pelatihan penggunaan software Maple dalam meningkatkan pemahaman materi olimpiade sains bagi guru matematika tingkat SMA se Kabupaten Pelalawan ini dapat disimpulkan berjalan dengan sangat baik. Pihak sekolah SMAN 1 Pangkalan Kerinci sangat membantu terutama dalam memberikan tempat penyelenggaraan kegiatan. Seluruh peserta pelatihan sangat antusias mengikuti kegiatan dari awal sampai berakhirnya kegiatan. Kegiatan yang direncakan sebanyak empat kali pertemuan dapat dipenuhi dengan baik. Luaran yang diharapkan dari kegiatan ini berupa modul pembelajaran dapat dibuat dan digunakan pada akhir kegiatan. Seluruh peserta sangat berharap agar kegiatan yang serupa kembali dilaksanakan di tempat mereka.

Berdasarkan hasil pengabdian ini disarankan untuk guru agar melakukan pengembangan untuk materi-materi lainnya. Selain itu juga diharapkan guru-guru yang sudah mengikuti kegiatan ini dapat menularkan ilmunya kepada guru lain yang belum bisa diundang dalam kegiatan ini. 


\section{DAFTAR PUSTAKA}

[1]. Kementerian Pendikan dan Kebudayaan Republik Indonesia. (2018). Panduan Pelaksanaan Olimpiade Sains Nasional Tahun 2018. Jakarta : Direktorat Pembinaan Sekolah Menengah Atas.

[2]. Rajali Rasyis. 2006. Pembinaan Olimpiade sains Binaan IPA Tingkat Sekolah Dasar. Jakarta : Tim Pembina IMSO (makalah)

[3]. Zulfarina dkk. 2012. Persiapan Siswa Dalam menghadapi OSN dengan Pembinaan Guru Pendamping OSN SMP di Kota Dumai. http://repository.unri.ac.id/

[4]. Widdya Rahmalina dkk, 2018, Pelatihan Aplikasi Maple pada Mata Pelajaran Matematika, Jurnal Pengabdian Masyarakat Universitas Abdurrab vol 2 No.3. 